\title{
Kontrol Tracking Fuzzy Menggunakan Model Following untuk Sistem Pendulum Kereta
}

\author{
Jimmy Hennyta Satya Putra, Trihastuti Agustinah \\ Teknik Elektro, Fakultas Teknologi Industri, Institut Teknologi Sepuluh Nopember (ITS) \\ Jl. Arief Rahman Hakim, Surabaya 60111 Indonesia \\ e-mail: trihastuti@elect-eng.its.ac.id, onehopecanhelp@gmail.com
}

\begin{abstract}
Abstrak-Sistem pendulum kereta memiliki karakteristik yang tidak stabil dan nonlinear. Pada makalah ini membahas tentang kontrol tracking dengan menggunakan struktur kontrol berbasis model following. Permasalahan dalam desain struktur kontrol tracking pada sistem pendulum kereta ini adalah bagaimana membuat posisi kereta dapat mengikuti sinyal referensi dengan tetap mempertahankan batang pendulum pada posisi equilibriumnya yaitu pada sudut nol radian. Model nonlinear dari sistem pendulum kereta direpresentasikan sebagai model fuzzy TakagiSugeno. Berdasarkan model tersebut, aturan kontroler disusun menggunakan konsep Parallel Distributed Compensation (PDC) berbasis teknik kontrol optimal. Hasil simulasi dan implementasi menunjukkan bahwa posisi kereta dapat mengikuti sinyal referensi tanpa adanya beda fasa antara respon posisi kereta terhadap sinyal referensi. Sinyal referensi sinus memberikan performansi tracking terbaik, dengan Integral Absolute Error (IAE) terkecil diantara sinyal referensi lain, yaitu pada simulasi sebesar 0,2622 dan pada implementasi sebesar 0,8477
\end{abstract}

Kata Kunci-Sistem pendulum kereta, fuzzy TakagiSugeno, Tracking

\section{PENDAHULUAN}

Dalam perkembangan ilmu pengetahuan dan teknologi di kehidupan sehari-hari. Sistem pendulum kereta merupakan suatu sistem yang sangat penting dalam penelitian di bidang kontrol. Berbagai teori metode kontrol banyak diuji, dibandingkan melalui pengujian terhadap sistem pendulum kereta. Hal ini dikarenakan sistem pendulum kereta merupakan sistem nonlinear yang kompleks dan tidak stabil serta dapat dilinearkan di sekitar titik keseimbangan. Sistem seperti ini dapat ditemukan pada robot humanoid dan alat transportasi segway.

Permasalahan kontrol yang biasa terdapat pada sistem pendulum kereta [1], dan [2] adalah swing-up, stabilisasi, dan tracking. Swing-up merupakan upaya yang dilakukan untuk mengayunkan batang pendulum dari posisi menggantung ke posisi berbalik. Stabilisasi merupakan upaya untuk mempertahankan kestabilan batang pendulum pada posisi terbalik. Sedangkan tracking merupakan upaya untuk mengontrol kereta agar bergerak mengikuti sinyal referensi dan tetap melakukan stabilisasi.

Permasalahan yang akan diselesaikan adalah tracking. Mengacu pada yakni penyelesaian yang dilakukan dengan merancang kontroler berbasis fuzzy. Penggunaan kontroler fuzzy dipilih karena memiliki perhitungan matematis yang sederhana. selanjutnya dilakukan stabilisasi sistem pendulum kereta di sekitar titik equilibriumya.

Perilaku nonlinear sistem pendulum kereta dapat direpresentasikan dengan menggunakan model fuzzy. Langkah awal yang perlu dilakukan adalah merepresentasikan plant lokal yang dinamis dari perbedaan daerah titik kerja ke model linear. Kemudian dibuat model dan aturan fuzzy yang sesuai untuk dapat melakukan kontrol tracking pada sistem pendulum kereta dengan metode fuzzy menggunakan model following agar sistem pendulum kereta mampu bergerak mengikuti sinyal referensi dengan tetap mempertahankan batang pendulum dalam posisi terbaliknya.

Pada [1] struktur kontrol tracking dengan LQT (Linear Quadratic Tracking) menggunakan model referensi untuk memodelkan sinyal referensinya. Dan pada riset tersebut menggunakan tiga sinyal referensi dalam pengujian secara simulasi dan implementasi. Dan pada [2] juga dikembangkan kontrol tracking menggunakan struktur kontrol servo tipe 1 tanpa integrator dengan menggunakan sinyal referensi step untuk sistem pendulum beroda dua.

\section{MODEL MATEMATIKA}

Sistem pendulum kereta terdiri dari dua bagian utama yaitu, kereta dan pendulum. Pemodelan sistem dengan model matematis diperoleh berdasarkan dinamika dari dua bagian utama sistem tersebut. Dengan melihat model dari sistem pendulum kereta pada Gambar 1, seorang perancang sistem kontrol dapat mengetahui gaya-gaya yang bekerja pada sistem pendulum kereta. Karena dalam membuat pemodelan suatu plant dapat dilakukan dengan dua cara yaitu dengan pemodelan secara hukum fisika (Hukum Newton II) dan pemodelan secara matematis dengan menggunakan metode-metode pemodelan plant yang statis contohnya metode Viteckova, Latzel, dan untuk plant yang dinamis contohnya metode ARMA (Auto Regressive Moving Average). Pada sistem pendulum kereta, kereta hanya dapat bergerak ke kiri atau ke kanan (bidang horizontal), dan untuk pendulum yang menempel pada kereta bergerak secara rotasi (bidang vertikal). Sistem pendulum kereta memiliki empat state yaitu $x_{1}, x_{2}, x_{3}$ dan $x_{4}$. Dengan $x_{1}$ adalah posisi kereta (jarak terhadap pusat lintasan), $x_{2}$ adalah jarak sudut antara vertikal tegak dengan jatuhnya posisi batang pendulum, $x_{3}$ adalah kecepatan kereta dan $x_{4}$ adalah kecepatan sudut batang pendulum. 


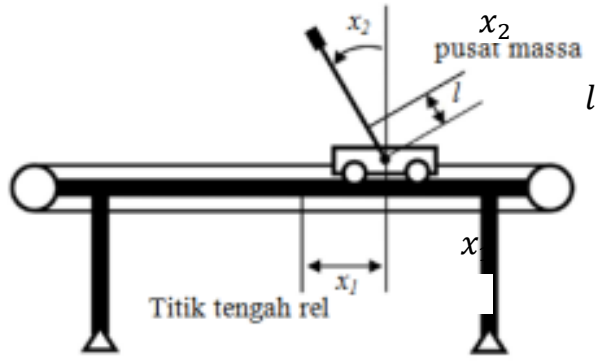

Gambar 1 Diagram Fisik Sistem Pendulum Kereta [3]

Model matematika dalam bentuk persamaan state dapat dituliskan sebagai berikut:

$$
\begin{aligned}
& \dot{x}_{1}=x_{3} \\
& \dot{x}_{2}=x_{4}
\end{aligned}
$$

a

dari sistem pendulum kereta sehingga dapat mengikuti sinyal referensi yang diberikan sekaligus menjaga keseimbangan batang pendulum dari sistem tersebut supaya tetap pada posisi terbalik.

Model matematis sistem pendulum kereta yang linear memiliki parameter-parameter pada matriks A dan B pada tiap model plant dengan 3 titik kerja berbeda,

Untuk titik kerja pertama:

$$
\begin{gathered}
\mathbf{x}=\left[\begin{array}{llll}
0 & 0 & 0 & 0
\end{array}\right]^{T} \text { dan } u=0 \text { diperoleh: } \\
\mathbf{A}_{1}=\left[\begin{array}{cccc}
0 & 0 & 1 & 0 \\
0 & 0 & 0 & 1 \\
0 & 0,2524 & 0 & -0,0001 \\
0 & 15,0319 & 0 & -0,0079
\end{array}\right] ; \mathbf{B}_{1}=\left[\begin{array}{c}
0 \\
0 \\
0,8272 \\
1,2370
\end{array}\right]
\end{gathered}
$$

Untuk titik kerja kedua:

$$
\begin{aligned}
& \mathbf{x}=\left[\begin{array}{llll}
0 \pm 0,3 & 0 & 0
\end{array}\right]^{T} \text { dan } u=0 \text { diperoleh: } \\
& \mathbf{A}_{2}=\left[\begin{array}{cccc}
0 & 0 & 1 & 0 \\
0 & 0 & 0 & 1 \\
0 & 0,2068 & 0 & -0,0001 \\
0 & 14,2640 & 0 & -0,0079
\end{array}\right] ; \mathbf{B}_{2}=\left[\begin{array}{c}
0 \\
0 \\
0,8254 \\
1,1791
\end{array}\right]
\end{aligned}
$$

Untuk titik kerja ketiga:

$$
\begin{aligned}
& \mathbf{x}=\left[\begin{array}{llll}
0 \pm 0,5 & 0 & 0
\end{array}\right]^{T} \text { dan } u=0 \text { diperoleh: } \\
& \mathbf{A}_{3}=\left[\begin{array}{cccc}
0 & 0 & 1 & 0 \\
0 & 0 & 0 & 1 \\
0 & 0,1333 & 0 & -0,0001 \\
0 & 12,9598 & 0 & -0,0079
\end{array}\right] ; \mathbf{B}_{3}=\left[\begin{array}{c}
0 \\
0 \\
0,8224 \\
1,0792
\end{array}\right]
\end{aligned}
$$

Matriks keluaran untuk ketiga titik operasi tersebut adalah sebagai berikut:

$$
\mathbf{C}_{\mathbf{1}}=\mathbf{C}_{\mathbf{2}}=\mathbf{C}_{\mathbf{3}}=\left[\begin{array}{llll}
1 & 0 & 0 & 0
\end{array}\right]
$$

$$
\begin{aligned}
& \dot{x}_{3}=\frac{a\left(u-T_{c}-\mu x_{4}{ }^{2} \sin x_{2}\right)+l \cos x_{2}\left(\mu g \sin x_{2}-f_{p} x_{4}\right)}{J+\mu l \sin ^{2} x_{2}} \\
& \dot{x}_{4}=\frac{l \cos x_{2}\left(u-T_{c}-\mu x_{4}{ }^{2} \sin x_{2}\right)+\mu g \sin x_{2}-f_{p} x_{4}}{J+\mu l \sin ^{2} x_{2}}
\end{aligned}
$$

dengan:

$$
\begin{aligned}
& a=l^{2}+\frac{J}{m_{c}+m_{p}} \\
& \mu=\left(m_{c}+m_{p}\right) l
\end{aligned}
$$

\section{KONTROL TRACKING FUZZY MENGGUNAKAN MODEL FOLLOWING}

Kontrol tracking fuzzy dengan menggunakan model following dirancang untuk mengontrol posisi keret

Dari parameter-parameter matriks A dan B ini, maka dapat dibangun model fuzzy T-S untuk plant sistem pendulum kereta dengan rule sebagai berikut.

Aturan plant ke-1:

$$
\begin{aligned}
& \text { If } x_{2}=M_{1} \text { (Sekitar 0 radian) } \\
& \text { Then } \begin{aligned}
\dot{\mathbf{x}} & =\mathbf{A}_{\mathbf{1}} \mathbf{x}+\mathbf{B}_{\mathbf{1}} u \\
y & =\mathbf{C}_{\mathbf{1}} \mathbf{x}
\end{aligned}
\end{aligned}
$$

Aturan plant ke-2:

$$
\begin{aligned}
& \text { If } x_{2}=M_{2}( \pm 0,3 \text { radian }) \\
& \text { Then } \begin{aligned}
\dot{\mathbf{x}} & =\mathbf{A}_{2} \mathbf{x}+\mathbf{B}_{2} u \\
y & =\mathbf{C}_{2} \mathbf{x}
\end{aligned}
\end{aligned}
$$

Aturan plant ke-3:

$$
\begin{aligned}
& \text { If } x_{2}=M_{3}( \pm 0,5 \text { radian }) \\
& \text { Then } \begin{aligned}
\mathbf{x} & =\mathbf{A}_{3} \mathbf{x}+\mathbf{B}_{3} u \\
y & =\mathbf{C}_{3} \mathbf{x}
\end{aligned}
\end{aligned}
$$

Model following dirancang berdasarkan sinyal referensi. Dalam bentuk persamaan state, model sinyal tersebut dinyatakan dalam bentuk:

$$
\begin{aligned}
& \dot{\mathbf{x}}_{r}=\mathbf{A}_{\mathbf{r}} \mathbf{x}_{r} \\
& y_{r}=\mathbf{C}_{\mathbf{r}} \mathbf{x}_{\mathbf{r}}
\end{aligned}
$$

Jika dihubungkan dengan plant yang dikontrol dengan menganggap sinyal tracking error $\mathrm{e}=\mathrm{r}-\mathrm{y}$ sebagai masukan dari model, maka akan diperoleh:

$$
\begin{aligned}
\dot{\mathbf{x}}_{\mathbf{c}} & =\mathbf{A}_{\mathbf{c}} \mathbf{x}_{c}+\mathbf{B}_{\mathbf{c}} e \\
y_{r} & =\mathbf{x}_{\mathbf{c}}
\end{aligned}
$$

dengan

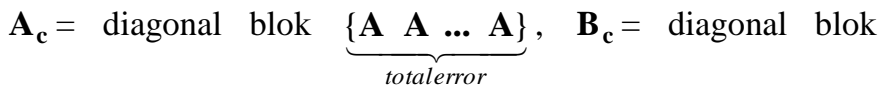

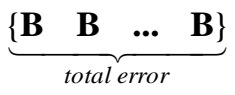


$A$ adalah matriks polynomial karakteristik dari sinyal referensi, misal, $\phi(s)=s^{l}+\alpha_{l-1} s^{l-1}+\ldots+\alpha_{1} s+\alpha_{0}$, sehingga

$$
\mathbf{A}=\left[\begin{array}{cccc}
0 & & & \\
\vdots & & I_{l-1} & \\
0 & & & \\
-\alpha_{0} & -\alpha 1 & \cdots & -\alpha_{l-1}
\end{array}\right], \quad \mathbf{B}=\left[\begin{array}{c}
0 \\
\vdots \\
0 \\
1
\end{array}\right]
$$

Dari Gambar 2, bila model following seperti pada Persamaan (9) dan persamaan state dari plant

$$
\begin{aligned}
& \dot{\mathbf{x}}=\mathbf{A x}+\mathbf{B} u \\
& y=\mathbf{C x}
\end{aligned}
$$

Maka dapat dibuat perluasaan sistem dalam bentuk matriks

$$
\left[\begin{array}{c}
\dot{\mathbf{x}} \\
\dot{\mathbf{x}}_{c}
\end{array}\right]=\left[\begin{array}{cc}
\mathbf{A} & 0 \\
-\mathbf{B}_{\mathbf{c}} \mathbf{C} & \mathbf{A}_{\mathbf{c}}
\end{array}\right]=\left[\begin{array}{l}
\mathbf{x} \\
\mathbf{x}_{\mathbf{c}}
\end{array}\right]+\left[\begin{array}{l}
\mathbf{B} \\
0
\end{array}\right] u+\left[\begin{array}{l}
0 \\
\mathbf{B}_{\mathbf{c}}
\end{array}\right] r
$$

Dan sinyal kontrol

$$
u=-\left[\begin{array}{ll}
\mathbf{K} & \mathbf{K}_{\mathbf{c}}
\end{array}\right]\left[\begin{array}{l}
\mathbf{x} \\
\mathbf{x}_{\mathbf{c}}
\end{array}\right]
$$

Dengan $\mathbf{K}$ adalah gain feedback dan $\mathbf{K}_{\mathbf{c}}$ adalah gain model following.

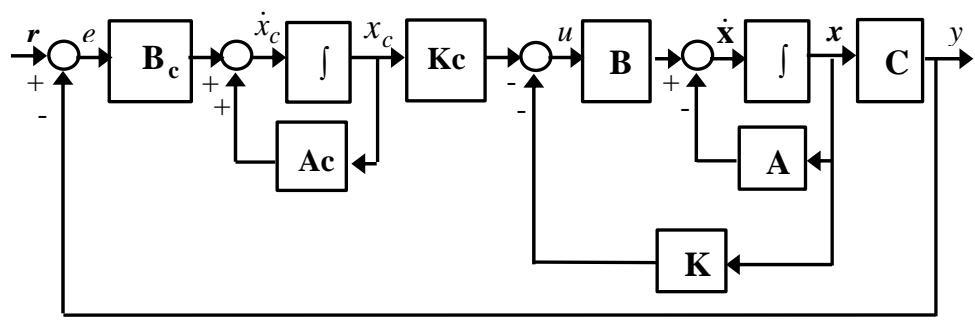

Gambar 2. Sistem Kontrol Tracking Model Following

Sinyal referensi digunakan untuk melakukan tracking pada sistem pendulum kereta agar sudut dari pendulum kereta berada pada titik equilibriumnya. Sinyal referensi yang digunakan adalah penjumlahan sinyal step dan sinus. Penjumlahan sinyal referensi ini dibutuhkan agar memenuhi matriks perluasan sistem (augmented system). Sinyal referensi yang diberikan adalah berupa penjumlahan sinyal step dan sinyal sinus dengan amplitudo $0,1 \mathrm{~m}$ dan frekuensi $0,1 \mathrm{~Hz}$. Dalam bentuk matematika sinyal referensi dapat dilihat pada Persamaan (13) berikut:

$$
\mathbf{r}(t)=u(t)
$$

Bentuk persamaan matematis untuk sinyal sinus, yaitu:

$$
\mathbf{r}(t)=\mathrm{A} \sin (2 \pi f t)
$$

Transformasi Laplace untuk sinyal step dan sinyal sinus adalah:

$$
\mathcal{L}[u(s)]=\frac{1}{s}
$$

dan

$$
\mathcal{L}[\sin \omega t]=\frac{\omega}{s^{2}+\omega^{2}}
$$

Setelah didapatkan bentuk Laplace dari sinyal step dan sinyal sinus maka akan diperoleh persamaan Laplace dari sinyal referensi pada Persamaan (9) berikut:

$$
\mathcal{L}[\mathbf{r}(s)]=\frac{0,0628}{s^{3}+0,3948 s}
$$

Persamaan state model following pada Persamaan (9) dapat dibangun berdasarkan sinyal referensi tersebut dengan

$$
\mathbf{A}_{\mathbf{c}}=\left[\begin{array}{ccc}
0 & 1 & 0 \\
0 & 0 & 1 \\
0 & -0,3948 & 0
\end{array}\right], \quad \mathbf{B}_{\mathbf{c}}=\left[\begin{array}{c}
0 \\
0 \\
0,0628
\end{array}\right]
$$

Dari bentuk matriks perluasan sistem (augmented system) seperti pada Persamaan (11) dan (12) dapat dibentuk tiga subsistem lup tertutup untuk ketiga model linear sistem pendulum kereta sebagai berikut:

$$
\begin{aligned}
& {\left[\begin{array}{cc}
\mathbf{A}_{1} & 0 \\
-\mathbf{B}_{\mathbf{c}} \mathbf{C}_{1} & \mathbf{A}_{\mathbf{c}}
\end{array}\right]-\left[\begin{array}{c}
\mathbf{B}_{1} \\
0
\end{array}\right]\left[\begin{array}{ll}
\mathbf{K}_{1} & \mathbf{K}_{\mathbf{c} 1}
\end{array}\right]} \\
& {\left[\begin{array}{cc}
\mathbf{A}_{2} & 0 \\
-\mathbf{B}_{\mathbf{c}} \mathbf{C}_{2} & \mathbf{A}_{\mathbf{c}}
\end{array}\right]-\left[\begin{array}{c}
\mathbf{B}_{2} \\
0
\end{array}\right]\left[\begin{array}{ll}
\mathbf{K}_{2} & \mathbf{K}_{\mathbf{c} 2}
\end{array}\right]}
\end{aligned}
$$

dan

$$
\left[\begin{array}{cc}
\mathbf{A}_{3} & 0 \\
-\mathbf{B}_{\mathbf{c}} \mathbf{C}_{\mathbf{3}} & \mathbf{A}_{\mathbf{c}}
\end{array}\right]-\left[\begin{array}{c}
\mathbf{B}_{\mathbf{3}} \\
0
\end{array}\right]\left[\begin{array}{ll}
\mathbf{K}_{\mathbf{3}} & \mathbf{K}_{\mathbf{c} 3}
\end{array}\right]
$$

Ketiga subsistem tersebut terdiri dari tujuh state, sehingga dibutuhkan penentuan tujuh nilai pada diagonal matriks pembobot Q. Pada makalah ini, matriks $\mathbf{Q}$ dan $\mathbf{R}$ ditentukan dengan cara trial and error dengan syarat matriks merupakan matriks simetris semi definit positif untuk $\mathbf{Q}$ dan matriks simetris definit positif untuk $\mathbf{R}$. Matriks $\mathbf{Q}$ dan $\mathbf{R}$ yang digunakan untuk tiga model linear pada makalah ini adalah:

$$
\begin{aligned}
& \mathbf{Q}_{1}=\operatorname{diag}\left(\left[\begin{array}{lllllll}
5000 & 8000 & 1 & 100 & 9.10^{6} & 9.10^{6} & 9.10^{6}
\end{array}\right]\right) \\
& \mathbf{R}_{1}=1
\end{aligned}
$$

Pada makalah ini, matriks $\mathbf{K}_{\mathrm{i}}$ dan $\mathbf{K}_{\mathrm{ci}}$ dihitung menggunakan bantuan program MATLAB dengan syntax lqr dengan nilai $\mathbf{Q}$ dan $\mathbf{R}$ sesuai dengan Persamaan (22) kemudian didapat:

$$
\begin{aligned}
& \mathbf{K}_{1}=\left[\begin{array}{llll}
-408,4869 & 541,7836 & -174,4043 & 139,7173
\end{array}\right] \\
& \mathbf{K}_{c 1}=\left[\begin{array}{lll}
3000 & 5,8591 & 9,2066
\end{array}\right]
\end{aligned}
$$




$$
\begin{aligned}
& \mathbf{K}_{2}=\left[\begin{array}{llll}
-414,1344 & 563,1131 & -178,7976 & 148,8645
\end{array}\right] \\
& \mathbf{K}_{c 2}=\left[\begin{array}{llll}
3000 & 5,8530 & 9,2618
\end{array}\right] \\
& \mathbf{K}_{3}=\left[\begin{array}{llll}
-425,1766 & 606,4374 & -187,5061 & 167,8159
\end{array}\right] \\
& \mathbf{K}_{c 3}=\left[\begin{array}{lll}
31623 & 5,8406 & 9,3684
\end{array}\right]
\end{aligned}
$$

Berdasarkan nilai dari gain-gain tersebut, dapat ditentukan aturan kontroler yang bersesuaian dengan aturan plant pada Persamaan (24) sampai (26) sebagai berikut.

Aturan Kontroler ke-1:

$$
\begin{aligned}
& \text { If } x_{2}=M_{1} \text { (Sekitar } 0 \text { radian) } \\
& \text { Then } \quad u=-\left[\begin{array}{ll}
\mathbf{K}_{\mathbf{1}} & \mathbf{K}_{\mathbf{c} 1}
\end{array}\right]\left[\begin{array}{l}
\mathbf{x} \\
\mathbf{x}_{\mathbf{c}}
\end{array}\right]
\end{aligned}
$$

Aturan Kontroler ke-2:

If $x_{2}=M_{2}( \pm 0,3$ radian $)$

$$
\text { Then } u=-\left[\begin{array}{ll}
\mathbf{K}_{2} & \mathbf{K}_{\mathbf{c} 2}
\end{array}\right]\left[\begin{array}{l}
\mathbf{x} \\
\mathbf{x}_{\mathbf{c}}
\end{array}\right]
$$

Aturan Kontroler ke-3:

If $x_{2}=M_{3}( \pm 0,5$ radian $)$

Then $u=-\left[\begin{array}{ll}\mathbf{K}_{\mathbf{3}} & \mathbf{K}_{\mathbf{c} \mathbf{3}}\end{array}\right]\left[\begin{array}{l}\mathbf{x} \\ \mathbf{x}_{\mathbf{c}}\end{array}\right]$

Model fuzzy T-S terlihat lebih sederhana pada proses defuzzifikasi dengan menggunakan metode rerata berbobot (weighted average), karena metode rerata berbobot merupakan metode khusus yang dapat digunakan untuk model fuzzy T-S.

Gambar 4 menunjukan fungsi keanggotaan fuzzy yang digunakan pada makalah ini. Fungsi keanggotaan yang dipilih adalah fungsi keanggotaan segitiga dan trapesium.

$M 1$ dan M2 adalah fungsi keanggotaan segitiga dengan parameter fungsi keanggotaan segitiga $\{a ; b ; c\}=\{-0,3 ; 0 ; 0,3\}$ dan $\{0 ; 0,3 ; 0.5\}$, sedangkan $M 3$ adalah fungsi keanggotaan trapesium dengan parameter fungsi keanggotaan trapesium $\{\mathrm{a} ; \mathrm{b} ; \mathrm{c} ; \mathrm{d}\}=\{0,3 ; 0,5 ; 2 ; 1,57\}$.

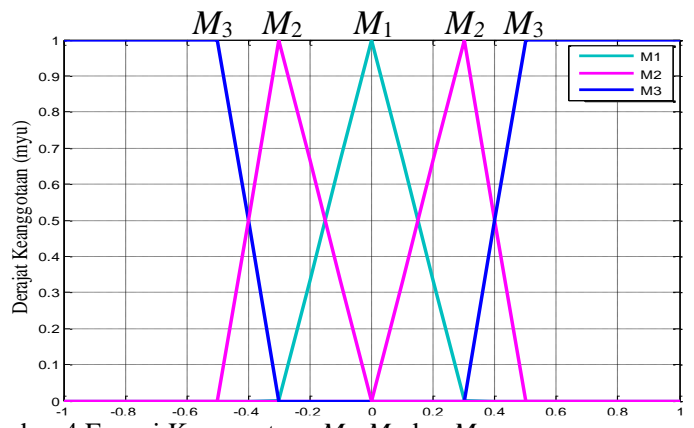

Gambar 4 Fungsi Keanggotaan $M_{1}, M_{2}$ dan $M_{3}$

\section{PENGUJIAN DAN ANALISIS}

Setelah proses perancangan sistem dan kontroler, selanjutnya dilakukan proses simulasi dan implementasi.
Simulasi sistem kontrol menggunakan perangkat lunak Simulink/MATLAB R2012. Model gaya gesek pada simulasi diabaikan karena nilai nya sangat kecil. Kondisi awal dari posisi pendulum sebesar 0,2 rad dan 0,3 rad. Kondisi awal tersebut terletak pada blok integrator pada sistem pendulum kereta. Sinyal referensi yang diberikan adalah sinyal step, sinus, dan square-wave.

\section{A. Simulasi}

Sinyal step yang digunakan pada simulasi dapat ditemukan pada library source pada Simulink. Nilai kondisi awal yang disimulasikan yaitu 0,2 dan 0,3 . Analisa yang dilakukan meliputi posisi kereta, posisi pendulum, dan sinyal kontrol. Hasil respon posisi kereta menggunakan sinyal referensi sinyal step dapat dilihat pada Gambar 5.

Gambar 5 menunjukan respon posisi kereta dalam satuan meter, dengan membandingkan respon posisi kereta pada kondisi awal berbeda terhadap sinyal referensi dengan amplitudo $0,1 \mathrm{~m}$ dan frekuensi $0,1 \mathrm{~Hz}$. Dalam menentukan karakteristik dari spesifikasi respon posisi kereta, posisi pendulum, dan sinyal kontrol bergantung pada kondisi awal dimana repon tersebut dimulai. Pada kondisi awal 0,2 respon posisi kereta memiliki nilai overshoot $-0,16$ meter, dan waktu yang dibutuhkan posisi kereta mampu mengikuti sinyal referensi sebesar 6 detik. Nilai overshoot respon posisi kereta lebih kecil yaitu $-0,15$ meter dan overshoot 0,19 meter didapatkan pada saat kondisi awal 0,3 dengan waktu posisi kereta dapat mengikuti sinyal referensi setelah 6 detik. Performansi tracking pada struktur kontrol hasil desain ini dapat dilihat bagaimana posisi kereta dapat mengikuti sinyal referensi dengan nilai error sekecil mungkin, pada pengujian dengan sinyal referensi step ini, performansi tracking didapatkan pada daerah steady state dari selisih sinyal referensi dengan hasil absolute respon output posisi kereta (Integral Absolute Error). Nilai IAE pada pengujian sinyal referensi step ini sebesar 0,845 .

Hasil respon posisi kereta menggunakan sinyal referensi sinus dapat dilihat pada Gambar 6. Gambar 6 menunjukan respon posisi kereta, dengan membandingkan respon posisi kereta pada kondisi awal berbeda. Pada kondisi awal 0,2 respon posisi kereta memiliki nilai overshoot $-0,14$ meter, dan waktu untuk posisi kereta dapat mengikuti sinyal referensi setelah 6 detik. Nilai overshoot respon posisi kereta lebih kecil yaitu 0,13 meter didapatkan pada saat kondisi awal 0,3 dengan waktu untuk posisi kereta dapat mengikuti sinyal referensi sama dengan pada kondisi 0,2 yaitu sebesar 6 detik. Performansi tracking dengan sinyal referensi sinus ini dihitung dengan Integral Absolute Error sebesar 0,1361.

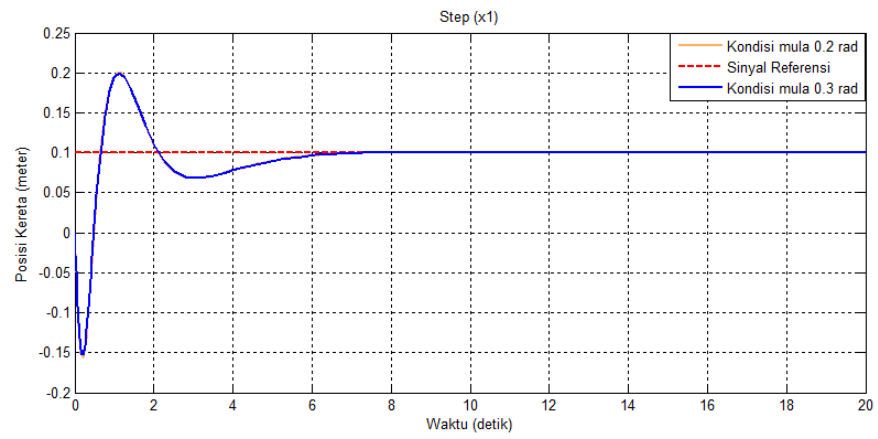


Gambar 5 Posisi Kereta dengan Sinyal Step

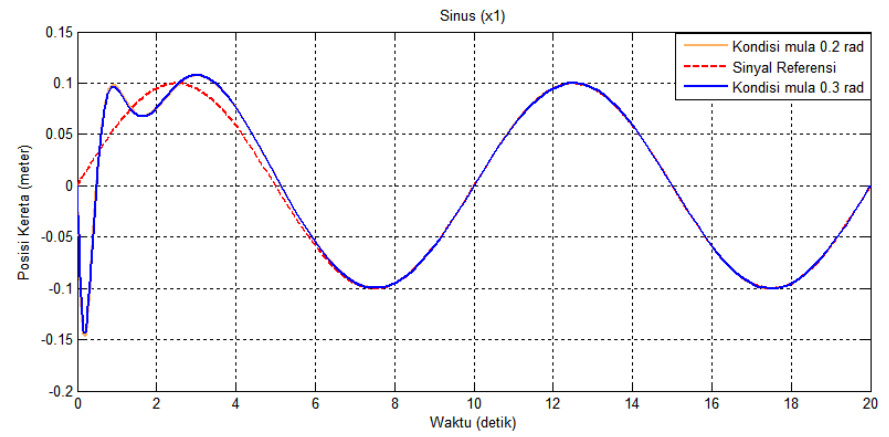

Gambar 6 Posisi Kereta dengan Sinyal Sinus

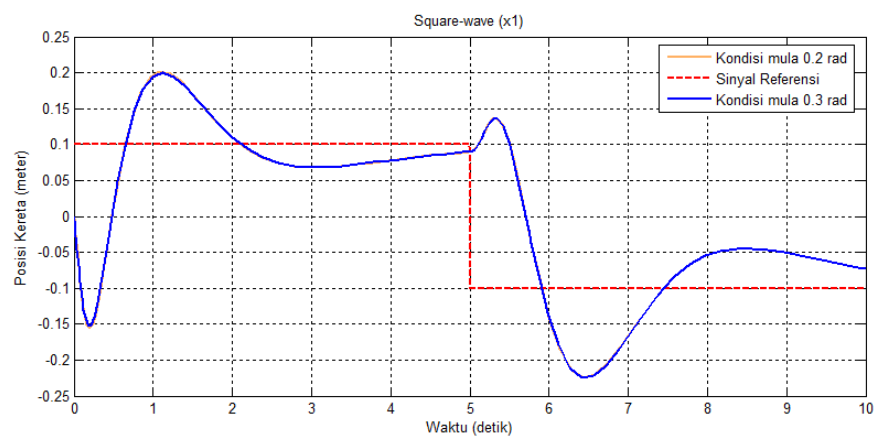

Gambar 7 Posisi Kereta dengan Sinyal Square-wave

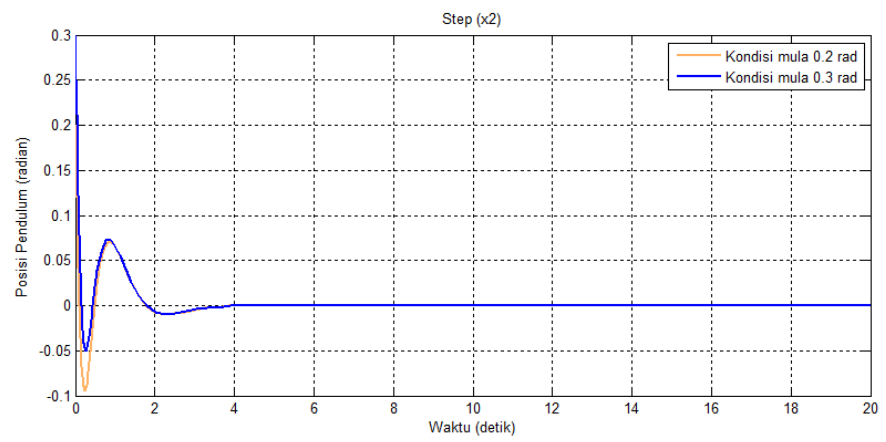

Gambar 8 Hasil Simulasi untuk Posisi Pendulum

Dalam sinyal square-wave terdapat range dan amplitudo yang membuat grafik sinyalnya pada posisi positif dan negatif. Hasil respon posisi kereta menggunakan sinyal referensi sinyal square-wave dapat dilihat pada Gambar 7. Respon posisi kereta yang ditunjukan membandingkan respon posisi kereta pada kondisi awal berbeda. Pada kondisi awal 0,2 respon posisi kereta memiliki nilai overshoot $-0,16$ meter. Kondisi awal 0,3 memiliki spesifikasi overshoot $-0,15$ meter. Performansi tracking dapat dilihat dari nilai IAE, pada pengujian dengan sinyal referensi square-wave ini, didapatkan nilai IAE sebesar 2,094. Performansi tracking dengan sinyal referensi sinus lebih baik dibandingkan dengan sinyal referensi step dan squarewave, karena hasil Integral Absolute Error tersebut menunjukan nilai Integral Absolute Error dengan sinyal referensi sinus lebih kecil dibandingkan sinyal referensi step. Struktur kontrol tracking yang baik adalah bagaimana membuat posisi kereta dapat mengikuti sinyal referensi seperti yang ditunjukan pada Gambar 5, 6, dan 7 dan tetap mempertahankan posisi pendulum disekitar titik equilibrium-nya, seperti yang ditunjukan pada Gambar 8.

\section{B. Implementasi}

Pada tahap implementasi ini, dilakukan pada plant nyata sistem pendulum kereta "Feedback Digital Pendulum System" dengan bantuan Simulink MATLAB. Alat real memiliki karakteristik gesekan pada bidang lintasan yang dinamis, sehingga kecepatan pendulum dan kecepatan kereta menjadi dinamis. Untuk meminimalisir terjadinya kerusakan alat pada AO card PCI 1711 atau plant sistem pendulum kereta, demi keamanan untuk tahap implementasi ini, sinyal kontrol yang dikirim ke sistem pendulum kereta real dibatasi $\pm 1,5$ Volt. Pemberian kondisi awal pada sudut pendulum ini dilakukan secara manual. Untuk sinyal referensi yang berikan berupa sinyal step dan sinus. Diamati dari pengujian simulasi dan implementasi dapat terlihat bahwa terdapat perbedaan pada hasil responnya, ini disebabkan saat implementasi penentuan kondisi mula dari posisi pendulum dilakukan secara manual, sehingga perbandingan posisi pendulum dapat dipengaruhi oleh noise pengukuran dari sensornya. Selain itu pula pada plant real kecepatan kereta dan kecepatan pendulum juga dapat mempengaruhi posisi kereta dan juga posisi pendulum, karena gesekan bidang lintasan yang dinamis.

Implementasi dilakukan untuk mengetahui pengaruh dari perancangan sistem kontrol yang sudah dibuat untuk diaplikasikan pada plant nyata sistem pendulum kereta dengan kondisi awal yang berbeda. Gambar 9 menunjukan respon posisi kereta dengan sinyal referensi step. Posisi kereta dapat mengikuti sinyal referensi, dengan nilai overshoot 0,0005 meter. Terlihat pada Gambar 9 respon posisi kereta mulai dapat mempertahankan posisinya di posisi 0,1 meter membutuhkan waktu 30 detik, dengan kisaran osilasi $\pm 0,07$ meter/detik. Performansi tracking untuk pengujian secara implementasi menggunakan sinyal referensi step ini didapatkan nilai IAE sebesar 0,845 .

Nilai referensi posisi kereta pada implementasi dengan sinyal sinus sama seperti pengujian sebelumnya yaitu 0,1 meter. Gambar 10 menunjukan respon posisi kereta tidak terdapat overshoot dengan waktu untuk posisi kereta dapat mengikuti sinyal referensi sebesar 19 detik. Performansi tracking untuk pengujian secara implementasi menggunakan sinyal referensi sinus ini menghasilkan nilai IAE sebesar 0,8477 .

Respon posisi kereta dengan sinyal referensi sinus tanpa gangguan dan dengan gangguan ditunjukan pada Gambar 11. Pada hasil respon posisi kereta dengan gangguan tersebut terlihat tidak terjadi overshoot dengan waktu yang dibutuhkan untuk posisi kereta dapat mengikuti sinyal referensi sebesar 19 detik. Terlihat jelas pada interval waktu 23 detik dan 28 detik, terdapat gangguan yang menyebabkan posisi kereta tidak dapat mengikuti sinyal referensi pada interval waktu gangguan tersebut, interval waktu ini sesuai karena masih masuk dalam range dari sinyal gangguan yang diberikan. Performansi tracking untuk posisi kereta pada pengujian secara implementasi menggunakan sinyal referensi sinus dengan gangguan ini didapatkan nilai IAE sebesar 0,9082. Pada pengujian secara implementasi ini dibuktikan bahwa posisi kereta dapat mengikuti sinyal referensi seperti yang ditunjukan pada Gambar 9, 10, 11 dan 12 dengan tetap mempertahankan posisi pendulum disekitar titik equilibriumnya seperti yang ditunjukan pada Gambar 12. 


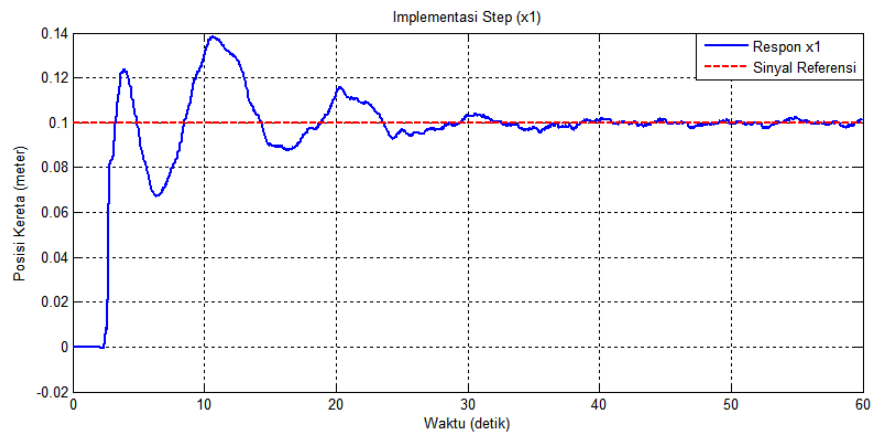

Gambar 9 Hasil Implementasi Sinyal Step untuk Posisi Kereta

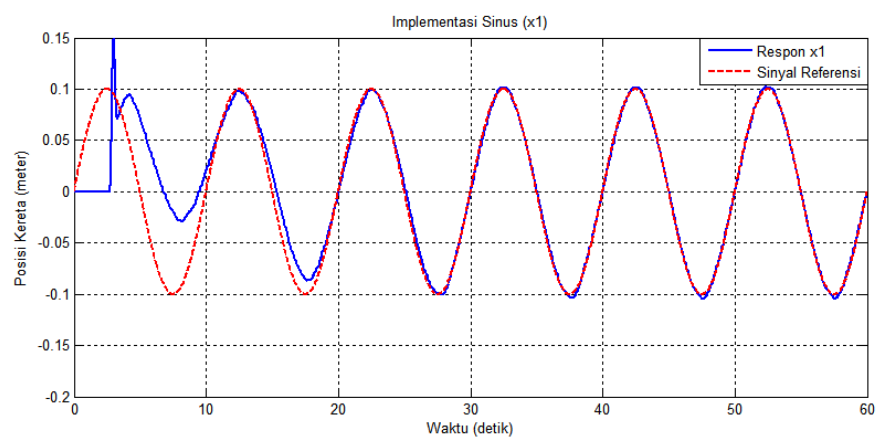

Gambar 10 Hasil Implementasi Sinyal Sinus untuk Posisi Kereta

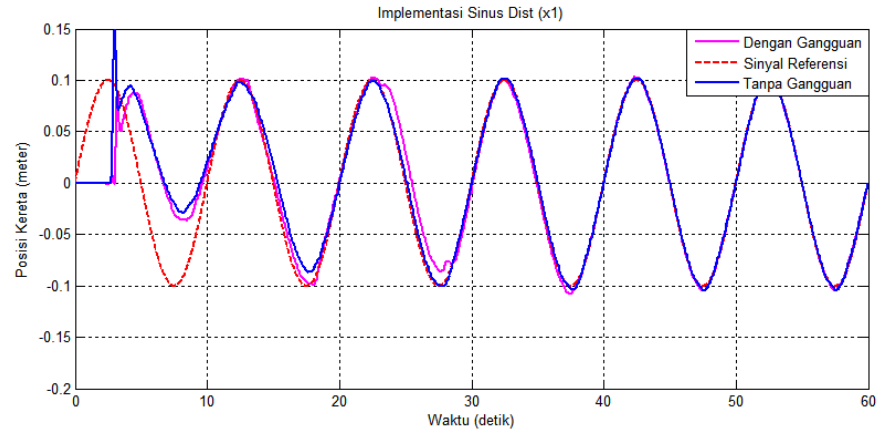

Gambar 11 Hasil Implementasi Sinyal Sinus dengan Gangguan untuk Posisi Kereta

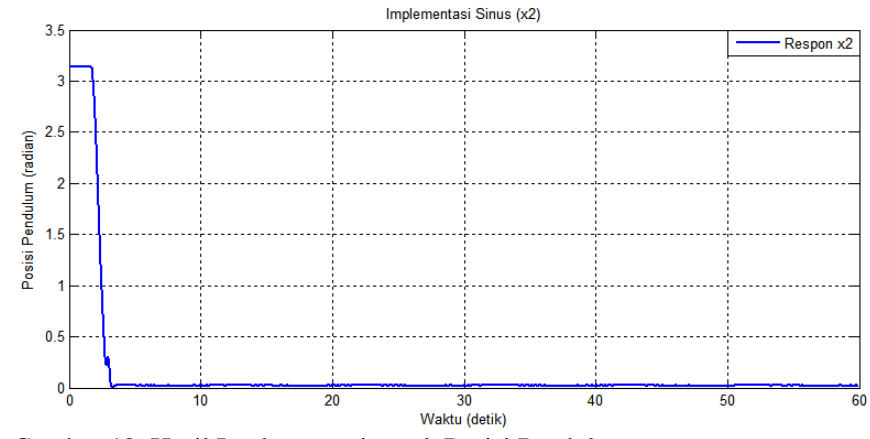

Gambar 12. Hasil Implementasi untuk Posisi Pendulum

\section{KESIMPULAN}

Membuat sesuatu yang kompleks menjadi sederhana merupakan salah satu cara berfikir sistem, ini terkait dengan pemahaman dari pembahasan yang terkait, tentunya jika dapat menguasai kemampuan secara teknis dipadu dengan cara berfikir sistem akan menjadi sesuatu yang lengkap dalam penelitian ini. Pada hasil pengujian dari simulasi dan implementasi ini dapat diambil beberapa poin penting tentang sistem kontrol tracking fuzzy menggunakan model following pada sistem pendulum kereta, kesimpulanya sebagai berikut:

1. Struktur kontrol tracking fuzzy menggunakan model following ini memiliki kelebihan dapat digunakan untuk tiga sinyal referensi yaitu sinyal step, sinus, dan square-wave tanpa adanya beda fasa terjadi antara sinyal referensi terhadap posisi kereta.

2. Dalam penentuan nilai pembobot matriks $\mathbf{Q}$ dan $\mathbf{R}$, didapatkan dengan trial and error. Terdapat ketentuanketentuan dalam pemilihan pembobot tersebut, yaitu nilai sinyal kontrol yang tidak melebihi $200 \mathrm{~N}$, eigen value yang didapatkan minimal -1 .

3. Pada pengujian simulasi dan implementasi menunjukan bahwa posisi kereta dapat mengikuti sinyal referensi yang diberikan dengan tetap mempertahankan sudut pendulum disekitar titik equilibriumnya.

4. Sinyal referensi sinus memberikan performansi tracking terbaik, dengan Integral Absolute Error (IAE) terkecil diantara sinyal referensi lain, yaitu pada simulasi sebesar 0,2622 dan pada implementasi sebesar 0,8477 .

\section{DAFTAR PUSTAKA}

[1]

[2]

[3]
Adenia, Rahma, "Kontrol Tracking Fuzzy-Optimal untuk Sistem Pendulum Kereta". Tugas Akhir Teknik Elektro ITS, Surabaya, 2013 Luthfi A., "Kontrol Tracking Optimal untuk Robot Pendulum Terbalik Beroda Dua," Tugas Akhir Teknik Elektro ITS, Surabaya, 2016 Feedback Instruments Ltd, "Digital Pendulum: Control in a MATLAB Environment (MATLAB 6.5 Version)",., 2004 